\title{
Risk assessment of metals in road-deposited sediment along an urban-rural gradient
}

\author{
Hongtao Zhao, Xuyong Li* \\ State Key Laboratory of Urban and Regional Ecology, Research Center for Eco-Environmental Sciences, Chinese Academy of Sciences, Shuangqing Road 18, Beijing 100085, China
}

\section{A R T I C L E I N F O}

\section{Article history:}

Received 1 November 2012

Received in revised form

6 December 2012

Accepted 13 December 2012

\section{Keywords:}

Road-deposited sediment

Metal pollution

Risk assessment methods

Urban-rural gradient

\begin{abstract}
A B S T R A C T
We applied the traditional risk assessment methods originally designed for soils and river sediments to evaluation of risk associated with metals in road-deposited sediment (RDS) along an urban-rural gradient that included central urban (UCA), urban village (UVA), central suburban county (CSA), rural town (RTA), and rural village (RVA) areas in the Beijing metropolitan region. A new indicator RI RDS $_{\text {was }}$ developed which integrated the RDS characteristics of mobility, grain size and amount with the potential ecological risk index. The risk associated with metals in RDS in urban areas was generally higher than that in rural areas based on the assessment using traditional methods, but the risk was higher in urban and rural village areas than the areas with higher administration units based on the indicator $\mathrm{RI}_{\mathrm{RDS}}$. These findings implied that RDS characteristics variation with the urban-rural gradient must be considered in metal risk assessment and RDS washoff pollution control.
\end{abstract}

(c) 2012 Elsevier Ltd. All rights reserved.

\section{Introduction}

Road surfaces serve as sinks and sources of metals and other contaminants in urban environments (Deletic and Orr, 2009; Yuen et al., 2012). Elevated concentrations of metals are ubiquitous in road-deposited sediment (RDS) owing to a wide range of human activities including vehicle emissions, coal combustion, disintegration of vehicle brakes and tires, atmospheric deposition, road surface wear, municipal solid waste incineration, and residential heating (Andrews and Sutherland, 2004; Duzgoren-Aydin, 2007; Eriksson et al., 2007; Duong and Lee, 2009). RDS acts as a significant carrier of potentially toxic elements such as metals including chromium $(\mathrm{Cr})$, copper $(\mathrm{Cu})$, nickel $(\mathrm{Ni})$, lead $(\mathrm{Pb})$ and zinc $(\mathrm{Zn})(\mathrm{Al}-$ Khashman, 2004; Tian et al., 2009; Sutherland et al., 2012). RDS contaminated by metals is becoming an important threat because of the possible transmission of their pollutants to aquatic systems by urban runoff (Herngren et al., 2005; Kong et al., 2012). Excessive accumulation of metals in RDS also results in increased human exposure to metals due to their close proximity to anthropogenic activities (Christoforidis and Stamatis, 2009; Charlesworth et al., 2011). As point source pollution is reduced in China and many other countries, urban runoff with contaminated RDS has become an increasingly serious problem (Zhu et al., 2008; Zhao et al., 2010). Thus, a proper understanding of RDS contamination is crucial in urban ecosystem.

\footnotetext{
* Corresponding author.

E-mail address: xyli@rcees.ac.cn (X. Li).
}

Good pollution assessment methods are powerful tools for processing, analyzing and conveying raw environmental information to decision makers, city planners, engineers and public health managers (Caeiro et al., 2005; Gong et al., 2008). In general, assessment of metal contamination of RDS is still in the initial stages. The earliest studies conducted to investigate metal contamination associated with RDS focused on comparison among land uses in one city or among different cities (Lau and Stenstrom, 2005; Lu et al., 2009). In recent years, a variety of methods have been introduced to investigate the metal risk associated with RDS posed to water, soil or river sediments, with traditional methods including the (1) geoaccumulation index ( $\left.I_{\text {geo }}\right),(2)$ enrichment factor (EF), (3) Nemerow synthetic pollution index $\left(\mathrm{PI}_{\mathrm{N}}\right)$ and (4) potential ecological risk index (RI) (Buccolieri et al., 2006; Cheng et al., 2007; Liu et al., 2008; Shi et al., 2010; Wei and Yang, 2010). The applicability of these traditional assessment methods to the risks associated with metals in RDS is still unclear. These methods were originally designed for the water, soil and river sediment, and only with consideration of metal concentrations or toxicology risks, without coupling the pollutant amounts and mobility to the grain size of the RDS. Clearly there is a need to develop a new method for assessment of metal risk associated with RDS characteristics.

The urban-suburban-rural gradient pattern is common in the context of rapid urbanization in China, and strongly affects land use zoning, population density, the proportion of surfaces that are impervious, traffic density, energy consumption, street cleaning methods, and spatial distribution of manufacturers (Callender and Rice, 2000; Zhao et al., 2011). Previous studies indicated that the 
urban-rural gradient had an important effect on RDS amounts, grain size composition, metal types and concentrations associated with it (Rogge et al., 1993; Kupiainen et al., 2005; Kim and Sansalone, 2008; Thorpe and Harrison, 2008). Zhao et al. (2011) reported that metal concentrations decreased and quantities of metals per unit area increased from urban to rural areas along the urban-rural gradient in Beijing. Therefore, the urban-rural gradient could strongly influence the spatial distribution of the potential risk of metals associated with RDS.

In this study, we aimed to 1) compare and analyze the applicability of traditional assessment methods to metal risk associated with RDS; 2) develop a new metal risk assessment method with consideration of RDS characteristics; and 3) investigate the spatial pattern of metal risk associated with RDS along an urban-rural gradient.

\section{Materials and methods}

\subsection{Study area and RDS sampling}

The administrative division of China has historically consisted of several levels. There are currently five practical levels of local government: the province, prefecture, county, township, and village. The administrative division in China is divided by political boundaries and not defined by quantified criteria, which results in several categories according to the characteristic of urban-rural function. The patterns of division differ only slightly and are followed by most large cities across the country. The administrative division of the urban-rural gradient in China is as follows: central urban (UCA), central suburban county (CSA), rural town (RTA), and rural village (RVA) areas. In addition, urban village areas (UVA) consist of villages within large cities that still look like rural villages and lack urban infrastructure and services, but are primarily occupied by residents that work in cities and have an urban lifestyle (Deng and Huang, 2004). There were obvious differences in land use zoning, population density, proportions of impervious surfaces, traffic density, energy consumption, street cleaning methods, and industry along the urban-rural gradient. Further details regarding the characteristics of sampling sites along the urban-rural gradient are available elsewhere (Supporting Information; Zhao et al., 2011). To account for variation in RDS characteristics on roads of areas, the number of sampling sites varied depending on our field investigation. For example, we selected four main traffic roads as our sampling sites of the CSA for each of the ten suburban counties (Fig. 1). We collected the RDS from all the ten suburban counties so that we could assure our sampling sites cover all suburban counties. The total sampling site number at the CSA was 10 CSA areas $\times 4$ main traffic roads $=40$ sampling sites. Based on our on-site investigation, we found that the characteristics of the UCA RDS had relatively lower variation. Eleven sampling sites were selected to represent the major roads of the UCA. Because of the smaller area of RTA and lower RDS variation of the RTA, RVA and UVA, we selected $20(10 \mathrm{RTA} \times 2$ main traffic roads), 20 (10 RVA $\times 2$ main traffic roads) and 6 ( $3 \mathrm{UVA} \times 2$ main traffic roads) sampling sites, for RTA, RVA, and UVA, respectively.

We collected RDS samples (1) during a dry weather period of about 2 weeks; (2) at a time that was half-way between the last sweeping time and the next; (3) so that the collection of all RDS samples in the study were completed in as short a time period as possible (eight days in this study). RDS samples were collected using a domestic vacuum cleaner (Philips FC8264) from September 2-10, 2009. For each RDS sample collection, a variable area was vacuumed from the central road marking to the curb, after which the sampling area length and width was measured with a ruler. All RDS samples were air-dried for 7 days and then weighed using an electronic scale. The sample mass ranged from 0.8 to $1.5 \mathrm{~kg}$. Samples were sorted into grain size fractions of $<44,44-62,62-105,105-149,149-250,250-450,450-1000$ and $>1000 \mu \mathrm{m}$ using polyester sieves.

\subsection{Analytical methods and quality control}

Total metals $\left(\mathrm{Cr}, \mathrm{Cu}, \mathrm{Ni}, \mathrm{Pb}\right.$ and $\mathrm{Zn}$ ) were measured after $\mathrm{HF}-\mathrm{HClO}_{4}$ digestion on a hotplate (Tessier et al., 1979). A quality control programme, including reagent blanks, replicate samples and standard reference material, was used to assess data precision and accuracy (Sutherland and Tolosa, 2000; Al-Khashman, 2004). All chemicals used for metal measurements were guaranteed reagent. All glassware, polyethylene labware and Teflon tubes used in the analyses of metals were washed with detergent, acid-soaked and then rinsed thoroughly with deionized water. GBW07401 (GSS-1) and GBW07402 (GSS-2), which are reference materials for soil certified by the General Administration of Quality Supervision, Inspection and Quarantine of the People's Republic of China (CRMs), were used for quality control during the digestion of RDS. The digests were stored at $4{ }^{\circ} \mathrm{C}$ prior to analysis. The concentrations of $\mathrm{Cr}, \mathrm{Cu}, \mathrm{Ni}, \mathrm{Pb}$ and $\mathrm{Zn}$ were determined by inductively coupled plasma-optical emission spectrometry (ICP-OES) (Perkin-Elmer, USA). The recoveries varied among metals, but all fell within the range of $75-95 \%$. The precision was nearly $90 \%$ with a confidence level of $95 \%$.

\subsection{Traditional risk assessment methods originated from soils and sediments}

Direct comparison, geoaccumulation index ( $\left.I_{\text {geo }}\right)$, Nemerow synthetic pollution index $\left(\mathrm{PI}_{N}\right)$, and potential ecological risk index (RI) were used to assess the metals contamination of RDS with different grain sizes along the urban-rural gradient in Beijing (Table 1).

\subsubsection{Geoaccumulation index ( $\left.I_{\text {geo }}\right)$}

Pollution levels of metal in RDS could be characterized by the $I_{\text {geo }}$ value put forward by Müller (1969), which can be calculated by Eq. (1):

$I_{\text {geo }}=\log _{2}\left[\frac{C_{i j}}{1.5 C_{r i}}\right]$

where: $C_{i j}$ is the measured concentration of the examined metal $i$ in RDS with grain size $j$, and $C_{r i}$ is the background concentration of metal $i$. The $C_{r i}$ for $\mathrm{Cr}, \mathrm{Cu}, \mathrm{Ni}, \mathrm{Pb}$ and Zn was set as 31.1, 19.7, 27.9, 25.1 and $59.6 \mathrm{mg} / \mathrm{kg}$, respectively (Chen et al., 2004). Factor 1.5 was selected because of possible variations in background values for a given metal in the environment as well as very small anthropogenic influences. Müller (1969) proposed seven classes of the $I_{\text {geo, }}$, which are given in Table 1.

2.3.2. Nemerow synthetic pollution index $\left(P I_{N}\right)$

$\mathrm{PI}_{\mathrm{N}}$ was applied to assess soil environmental quality in previous studies (Cheng et al., 2007). In the present study, this method was utilized to measure the degree of RDS environmental pollution as follows:

$$
\begin{aligned}
\mathrm{PI}_{\mathrm{N}} & =\sqrt{\frac{\operatorname{Max}_{i j}^{2}+{\overline{P_{i j}}}^{2}}{2}} \\
& =\sqrt{\frac{\left[\frac{C_{i j}}{C_{r i}}\right]_{\operatorname{Max}}^{2}+\left[\frac{1}{m} \sum_{i=1}^{m} \frac{C_{i j}}{C_{r i}}\right]^{2}}{2}}
\end{aligned}
$$

where: Max $P_{i j}$ and $\overline{P_{i j}}$ are the maximum and average value of the pollution indices of all metals, respectively, $m$ is the number of metal species and $C_{i j}$ and $C_{r i}$ have the same meaning as in Eq. (1). Cheng et al. (2007) proposed five classes of $\mathrm{PI}_{N}$, which are shown in Table 1.

\subsubsection{Potential ecological risk index (RI)}

RI, which represents the sensitivity of the biological community to toxic substance and illustrates the potential ecological risk caused by the overal contamination, was introduced to assess the contamination degree of RDS in previous studies. The equation used to calculate RI was as follows (Hakanson, 1980):

$\mathrm{RI}=\sum_{i=1}^{m} T_{r}^{i} \times \frac{C_{i j}}{C_{r i}}$

where: RI is the sum of all five risk factors for metals in RDS, $T_{\mathrm{r}}^{\mathrm{i}}$ is the metal toxic response factor according to Hakanson (1980), and the values for each element are in the order of $\mathrm{Zn}=1<\mathrm{Cr}=2<\mathrm{Cu}=\mathrm{Ni}=\mathrm{Pb}=5$. $C_{i j}$ and $C_{r i}$ have the same meaning as in Eq. (1). Hakanson (1980) proposed four classes of RI, which are shown in Table 1.

\subsection{A new index for assessment of metal risk associated with RDS (RIRDS)}

The new method for assessment of metal risk associated with RDS, which coupled concentration, toxic response factor, and the pollutant amounts and mobility, was primarily based on RI. The equations comprising the potential ecological risk index of $\mathrm{RDS}\left(\mathrm{RI}_{\mathrm{RDS}}\right)$ are as follows:

$$
\begin{aligned}
\mathrm{RI}_{\mathrm{RDS}} & =\sum_{i}^{n}\left(\sum_{j}^{m} \mathrm{RI}_{j}\right) \times F_{\text {amount }} \times F_{\text {mobility }} \\
& =\sum_{i}^{n}\left(\sum_{j}^{m} \mathrm{RI}_{j}\right) \times\left(\sum_{j}^{m} A \times P_{i} \times M_{j}\right) \\
& =\sum_{j}^{m} \sum_{i}^{n}\left(T_{r}^{i} \times \frac{C_{i j}}{C_{r i}} \times A \times P_{j} \times M_{j}\right)
\end{aligned}
$$

where: $T_{r}^{i}$ has the same meaning as in Eq. (3) and $C_{i j}$ and $C_{r i}$ have the same meaning as in Eq. (1). A was the amount of RDS per unit area. The amounts of RDS per unit area varied with the site averaging from 26 to $220 \mathrm{~g} / \mathrm{m}^{2}$ (Sartor and Boyd 1972) and were divided into six levels: $0-30 \mathrm{~g} / \mathrm{m}^{2}=1.00 ; 31-60 \mathrm{~g} / \mathrm{m}^{2}=1.75 ; 61-$ $90 \mathrm{~g} / \mathrm{m}^{2}=2.50 ; 91-140 \mathrm{~g} / \mathrm{m}^{2}=3.00 ; 141-190 \mathrm{~g} / \mathrm{m}^{2}=3.50 ;>190 \mathrm{~g} / \mathrm{m}^{2}=3.75 . P$ was the percentage of RDS with grain size $j$ accounting for the total RDS mass and $M_{j}$ is the grain size response factors for potential mobility in runoff (Zhao et al., 2011) (Table 2). 


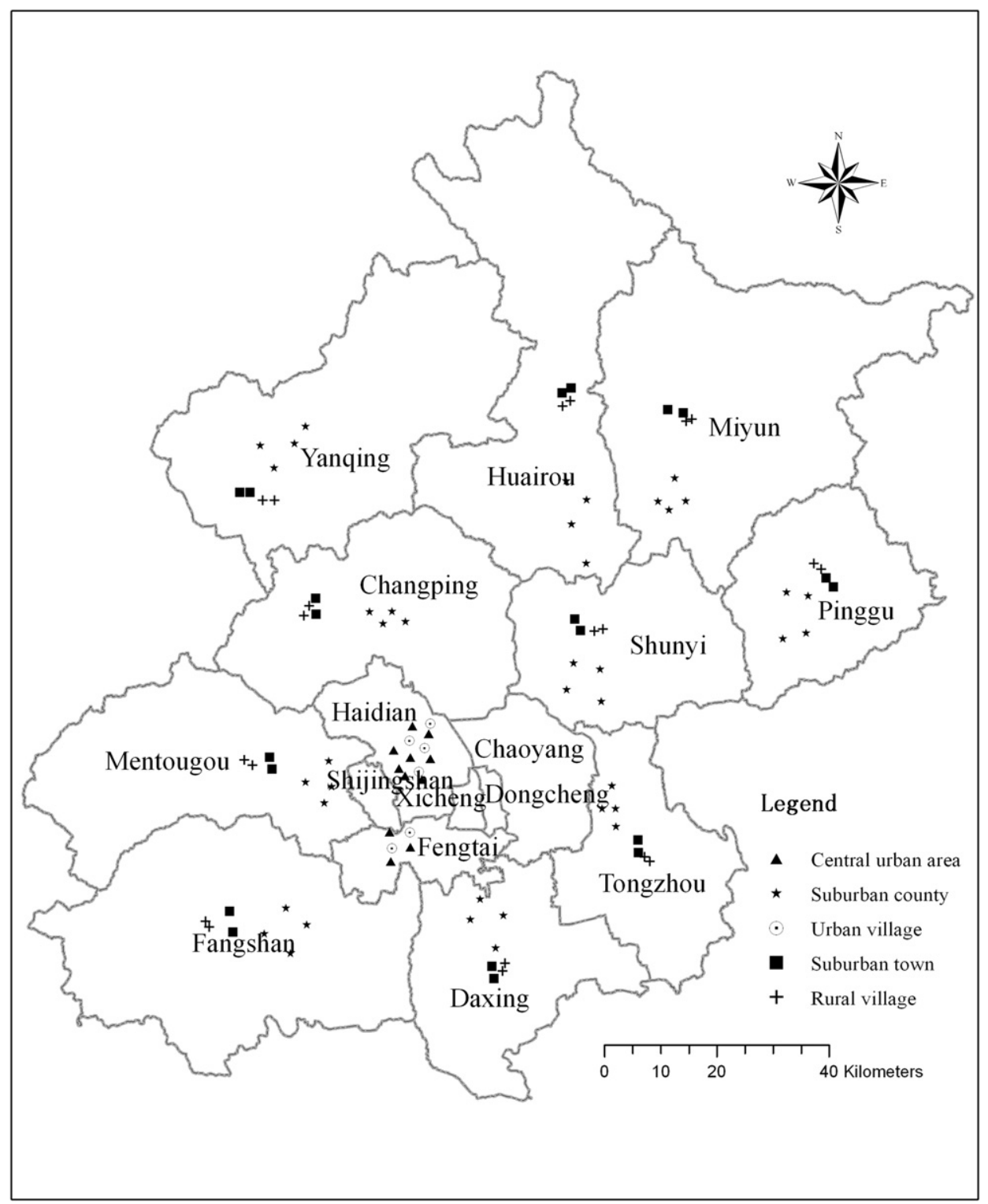

Fig. 1. Study area and sampling site locations in Beijing, China.

Table 1

A concise comparison of four metal assessment methods.

\begin{tabular}{|c|c|c|c|c|c|c|c|}
\hline Method name & Direct comparison & \multicolumn{2}{|c|}{ Geoaccumulation index $\left(I_{\text {geo }}\right)^{\mathrm{a}}$} & \multicolumn{2}{|c|}{$\begin{array}{l}\text { Potential ecological risk index } \\
(\mathrm{RI})^{\mathrm{b}}\end{array}$} & \multicolumn{2}{|c|}{ Nemerow pollution index $\left(\mathrm{PI}_{\mathrm{N}}\right)^{\mathrm{c}}$} \\
\hline Method focus & Comparable with each other & \multicolumn{2}{|c|}{ Background enrichment } & \multicolumn{2}{|l|}{ Ecological risk } & \multicolumn{2}{|c|}{ Multi-pollutants integration } \\
\hline Assessment base & $\begin{array}{l}\text { Single element total } \\
\text { concentration }\end{array}$ & \multicolumn{2}{|c|}{ Single element total concentration } & \multicolumn{2}{|c|}{$\begin{array}{l}\text { Multi-elements total } \\
\text { concentration }\end{array}$} & \multicolumn{2}{|c|}{$\begin{array}{l}\text { Multi-elements total } \\
\text { concentration }\end{array}$} \\
\hline Characteristics & $\begin{array}{l}\text { Pollution level compared } \\
\text { with each other in term of } \\
\text { total concentration }\end{array}$ & \multicolumn{2}{|c|}{$\begin{array}{l}\text { It enriches anthropogenic influences } \\
\text { from geochemical background. }\end{array}$} & \multicolumn{2}{|c|}{$\begin{array}{l}\text { It evaluates ecological risk based } \\
\text { on environmental chemistry for } \\
\text { different elements }\end{array}$} & \multicolumn{2}{|c|}{$\begin{array}{l}\text { It highlights the risk of high } \\
\text { concentration element while } \\
\text { integrates the others. }\end{array}$} \\
\hline \multirow{7}{*}{$\begin{array}{l}\text { Values and } \\
\text { categories }\end{array}$} & No. & $I_{\text {geo }} \leq 0$ & Unpolluted & $\mathrm{RI} \leq 50$ & Low risk & $\mathrm{PI}_{\mathrm{N}}<0.7$ & Safe \\
\hline & & $0<\bar{I}_{\text {geo }} \leq 1$ & Unpolluted/moderately & $50<\mathrm{RI} \leq 100$ & Moderate & $0.7 \leq \mathrm{PI}_{\mathrm{N}}<1.0$ & Precaution \\
\hline & & $1<I_{\text {geo }} \leq 2$ & Moderately & $100<\mathrm{RI} \leq 200$ & Considerable & $1.0 \leq \mathrm{PI}_{\mathrm{N}}<2.0$ & Slightly risk \\
\hline & & $2<I_{\text {geo }} \leq 3$ & Moderately/strongly & $\mathrm{RI}>200$ & High & $2.0 \leq \mathrm{PI}_{\mathrm{N}}<3.0$ & Moderately \\
\hline & & $3<I_{\text {geo }} \leq 4$ & Strongly & & & $\mathrm{PI}_{\mathrm{N}}>3.0$ & Seriously \\
\hline & & $4<I_{\text {geo }} \leq 5$ & Strongly/extremely & & & & \\
\hline & & & Extremely & & & & \\
\hline
\end{tabular}

a Müller (1969) and Buccolieri et al. (2006).

b Hakanson (1980).

c Cheng et al. (2007). 
Table 2

The grain size response factors for potential mobility in runoff.

\begin{tabular}{clllllll}
\hline $\begin{array}{l}\text { Response } \\
\text { factors }\left(R_{i}\right)\end{array}$ & \multicolumn{6}{l}{ Grain size fraction of RDS $(\mu \mathrm{m})$} \\
\cline { 2 - 7 } & $<44$ & $44-62$ & $62-105$ & $105-149$ & $149-250$ & $250-450$ & $450-1000$ \\
\hline $\begin{array}{c}\text { Mobility in } \\
\text { runoff }\end{array}$ & 17.0 & 10.0 & 4.5 & 4.3 & 2.9 & 1.5 & 1.0 \\
\hline
\end{tabular}

a The values of $R_{i}$ on each grain size fraction in runoff are calculated according to washoff percentages of RDS on each grain size fraction in Zhao et al. (2011); Assignment method: taking the minimum value as 1 ,other value of its in multiples.

\section{Results}

\subsection{Variation of metal concentrations in RDS along the urban-rural gradient}

Direct comparisons of concentrations are the simplest and most direct assessment method. Metal concentrations in Beijing RDS along the urban-rural gradient and grain size gradient are presented in Fig. 2a and b, respectively. Except for $\mathrm{Ni}$, the mean

\section{a}

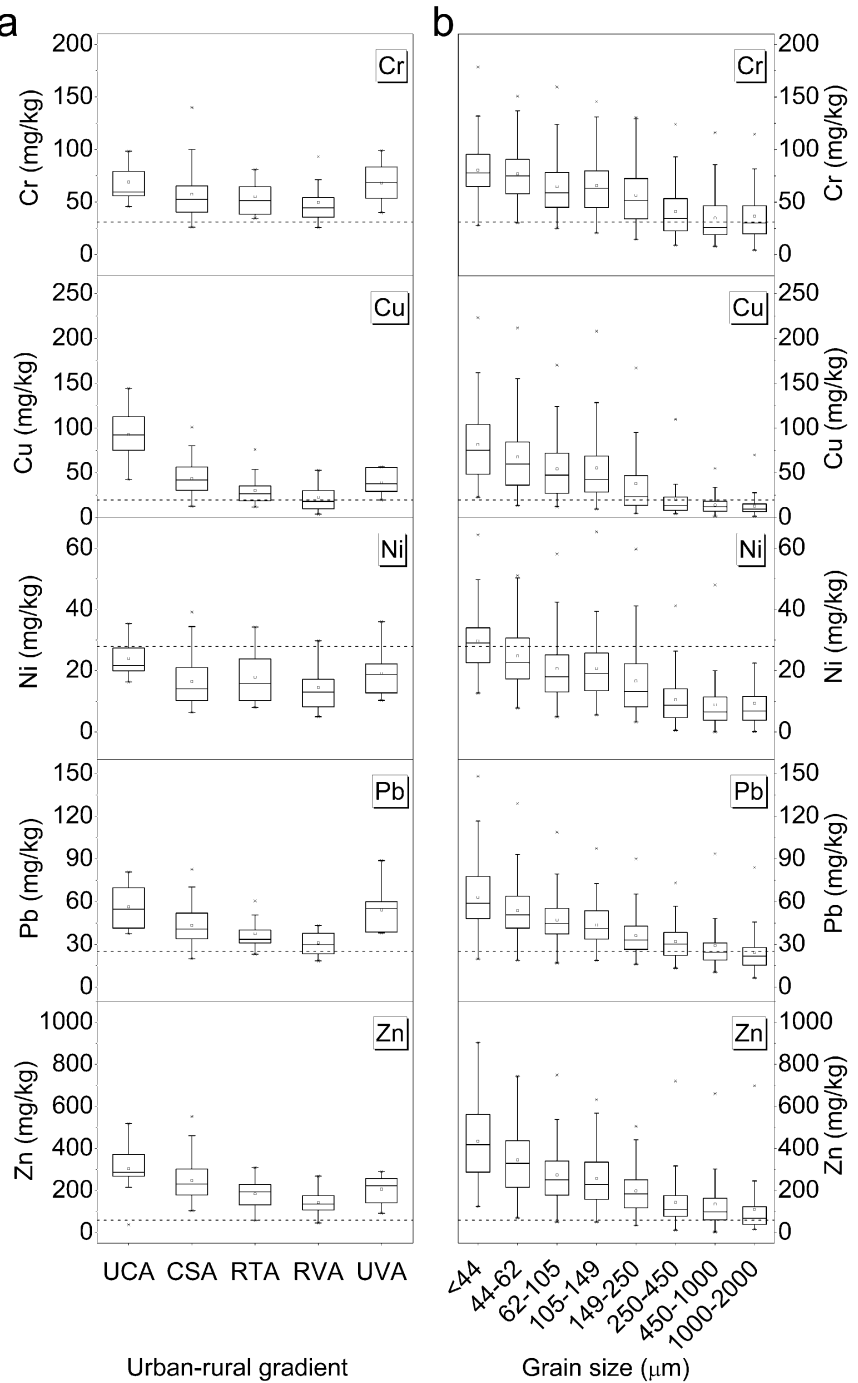

Fig. 2. Box plot of metals concentrations in road-deposited sediment of Beijing: (a) urban-rural gradient and (b) grain size gradient. Dashed lines on each subfigure refer to corresponding background values of Beijing soils (Chen et al., 2004). UCA = central urban area; $\mathrm{UVA}=$ urban village area; $\mathrm{CSA}=$ central suburban county area; $\mathrm{RTA}=$ rural town area; RVA = rural village area. concentrations of $\mathrm{Cr}, \mathrm{Cu}, \mathrm{Pb}$ and $\mathrm{Zn}$ in Beijing RDS were approximately $2-4$ fold higher than the corresponding background values of Beijing soils (Chen et al., 2004) (Fig. 2a). Along the urban-rural gradient, the mean concentrations for all metals combined decreased in the order of UCA $>$ CSA $\approx$ UVA $>$ RTA $>$ RVA.

As shown in Fig. 2b, grain size played an important role in the pollutant distribution in RDS. Specifically, RDS with coarser grain size had clearly lower metal concentrations and greater variability. In the process of RDS collection and grain size fractionation, we found RDS with coarser grain size have great heterogeneity, which could explain their high metal concentration variability relative to their low metal concentration.

\subsection{Risk assessment of metals derived from $I_{g e o}$}

The method of $I_{\text {geo, }}$, which was originally designed for river sediments, has commonly been used to evaluate background enrichment of metals. Along the urban-rural gradient, nearly all $I_{\text {geo }}$ values for $\mathrm{Cr}, \mathrm{Cu}, \mathrm{Pb}$ and $\mathrm{Zn}$ in $\mathrm{RDS}$ with grain size fractions of 0-2000 $\mu \mathrm{m}$ were $>0$ (Fig. 3a), indicating that RDS were contaminated by metals derived from anthropogenic sources. On average,

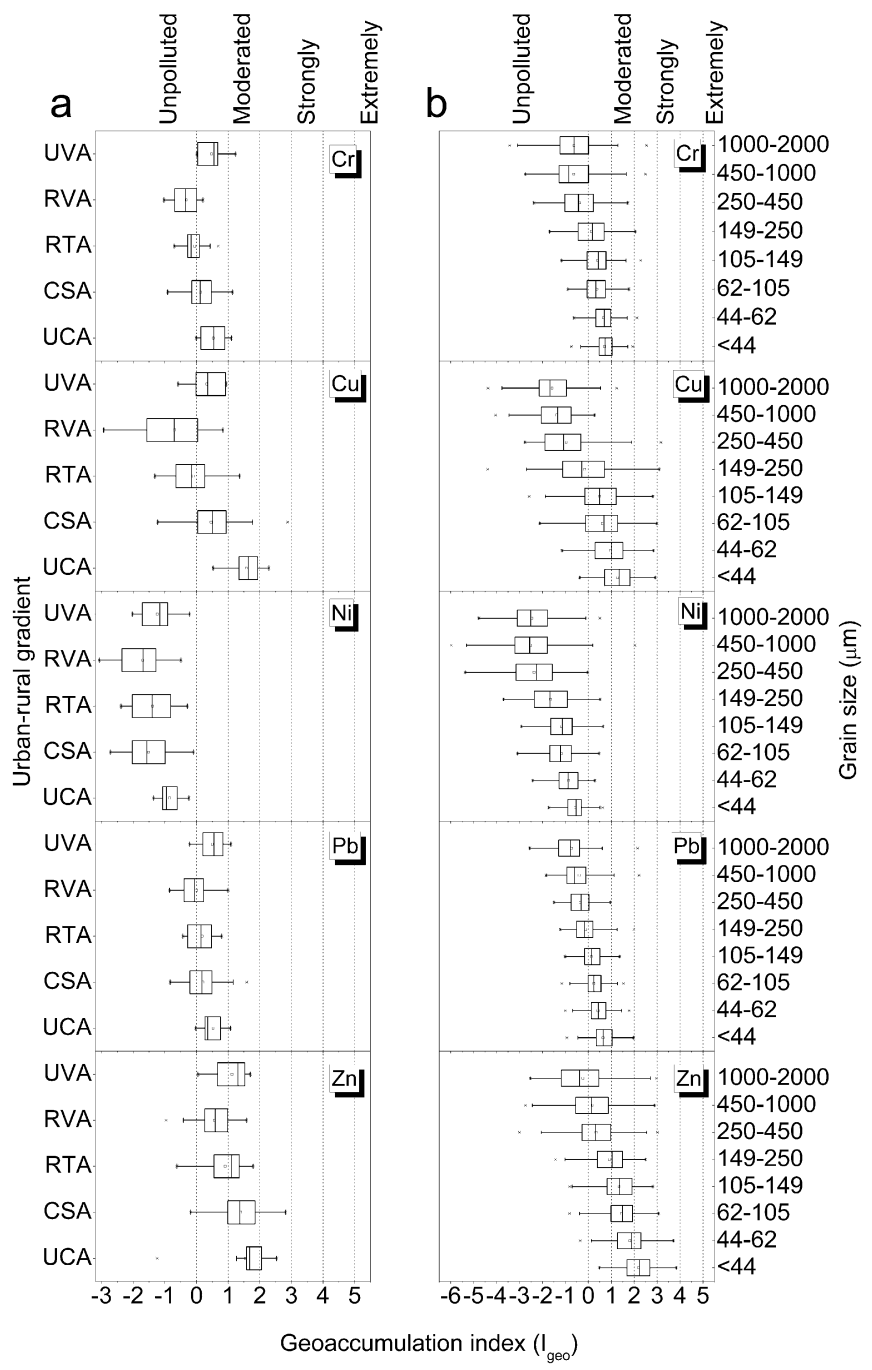

Fig. 3. Box plot of geoaccumulation index $\left(I_{\text {geo }}\right)$ of metals in road-deposited sediment of Beijing: (a) urban-rural gradient and (b) grain size gradient. UCA = central urban area; UVA = urban village area; CSA = central suburban county area; $\mathrm{RTA}=$ rural town area; RVA = rural village area 
the $I_{\text {geo }}$ values for $\mathrm{Cr}, \mathrm{Cu}$, and $\mathrm{Pb}$ ranged from unpolluted to moderate, except for $\mathrm{Cu}$ in RVA and RTA, and Pb in RVA. For Zn, all mean $I_{\text {geo }}$ values fell into the category of moderate contamination levels, except for $\mathrm{Zn}$ in RVA and RTA. Moreover, the $I_{\text {geo }}$ values for $\mathrm{Ni}$ were all below 0 , suggesting that $\mathrm{Ni}$ in RDS fell into the category of unpolluted. The above results were basically consistent with those of a previous study conducted in Beijing (Xiang et al., 2010). Overall, the $I_{\text {geo }}$ values for all metals combined decreased in the order of UCA $>$ CSA $\approx$ UVA $>$ RTA $>$ RVA, which was also consistent with the results of metal concentration comparisons along the urbanrural gradient.

To further understand the impact of grain size on the background enrichment of metals, Igeo was applied to RDS along the grain size gradient (Fig. 3b). RDS with coarser grain size clearly had wider $I_{\text {geo }}$ ranges relative to their low $I_{\text {geo }}$ values than those with smaller grain size. This could be attributed to the great heterogeneity in the coarser RDS. In addition, RDS with smaller grain size had higher contamination levels.

\subsection{Risk assessment of metals derived from $P I_{N}$}

While $I_{\text {geo }}$ reflects each metal, $\mathrm{PI}_{\mathrm{N}}$ is an integrated index of several metals. This method was used along the urban-rural and grain size gradients to evaluate metals pollution comprehensively (Table 3). For the urban-rural gradient, the $\mathrm{PI}_{\mathrm{N}}$ values of RDS of $0-$ $2000 \mu$ m decreased in the order of CSA $>$ UCA $>$ RTA $>$ UVA $>$ RVA, and all fell into the severe contamination level. The assessment results along the urban-rural gradient differed from the two methods above because this method highlighted the risk of high concentration elements, while these are integrated in the other methods.

Similar to the $I_{\text {geo }}$ method, RDS grain sizes also played an important role in assessing contamination levels. The grain sizes for moderate contamination levels of metals were less than $250 \mu \mathrm{m}$ for UCA, $62 \mu \mathrm{m}$ for CSA, $44 \mu \mathrm{m}$ for RTA, and $105 \mu \mathrm{m}$ for UVA. RDS with small grain sizes all had higher metal contamination levels. These results implied that smaller particles should receive greater attention because of their higher mobility.

\subsection{Risk assessment of metals derived from RI}

When compared to $\mathrm{PI}_{\mathrm{N}}$, RI is an integrated index of several metals that considers not only the concentration, but also the toxicity of metals. The calculated results of RI caused by the overall pollution $(\mathrm{Cr}, \mathrm{Cu}, \mathrm{Ni}, \mathrm{Pb}$ and $\mathrm{Zn}$ ) of RDS at grain sizes from 0 to $2000 \mu \mathrm{m}$ are presented in Fig. 4. For the urban-rural gradient, the mean values of RI of RDS with grain sizes of $0-2000 \mu \mathrm{m}$ decreased in the order of UCA $>$ CSA $\approx$ UVA $>$ RTA $>$ RVA (Fig. 4a). On average,
RI values falling into class I and II indicated low to moderate contamination.

Similar to the assessment methods above, RDS grain sizes had an important effect on assessment of the contamination levels. As shown in Fig. 4b, RDS with coarser grain size had lower RI values. Additionally, approximately $50 \%$ of RDS samples with a diameter $<44 \mu \mathrm{m}$ fell into the category of moderate contamination.

\subsection{Risk assessment of metals derived from $R_{R D S}$}

The four assessment methods described above all indicated that RDS grain size was the key factor influencing contamination levels. Thus, it was necessary to add the grain size to the ecological risk index (RDS mobility and amount). The factors of mobility added to the RI are listed in Table 4. The product of the two factors above was used to modify RI to assess metal risk associated with RDS to urban runoff (Table 5). In addition, risk values and categories for $\mathrm{RI}_{\mathrm{RDS}}$ method were also established according to the product of mobility and amount factor, and the original risk values and categories for RI. The $\mathrm{RI}_{\mathrm{RDS}}$ in runoff was classified as: $\mathrm{RI}_{\mathrm{RDS}} \leq 150$, low risk; $150<\mathrm{RI}_{\mathrm{RDS}} \leq 300$, moderate risk; $300<\mathrm{RI}_{\mathrm{RDS}} \leq 600$, considerable risk; $\mathrm{RI}_{\mathrm{RDS}}>600$ high risk.

The calculated results of $\mathrm{RI}_{\mathrm{RDS}}$ in runoff are presented in Fig. 5. The calculated $\mathrm{RI}_{\mathrm{RDS}}$ decreased in the order of UVA $>$ RVA $>$ UCA $>$ RTA $>$ CSA in runoff. RDS collected from UVA fell into the category of high risk. Because of the added factors of mobility and amount, the results of $\mathrm{RI}_{\mathrm{RDS}}$ along the urban-rural gradient were quite different from those of the RI.

\section{Discussion}

Multi-methods for metal assessment of RDS help understanding the uncertainty of the assessment results that commonly occurs when a single method is used. The assessment results for the same gradient units varied among urban-rural gradients using different methods (Table 6). Because the methods of direct comparison and $I_{\text {geo }}$ only focused on the total concentration of metals, UCA and CSA had a higher metals risk level than other gradient units. Considering the total metals concentrations and their individual toxicity, UCA and UVA had higher metals risk levels than other urban-rural gradient units determined using RI. While $\mathrm{PI}_{N}$ highlights the extreme value of total metal concentrations, CSA had the highest metal risk. The variation of the assessment results above could explain that different assessment methods have different method focus, assessment base and their characteristics (Table 1).

There hadn't been an assessment method specifically designed for assessment of the pollutants risk in RDS (Zhu et al., 2008; Xiang et al., 2010). In this study, the traditional assessment methods can

Table 3

Nemerow pollution index $\left(\mathrm{PI}_{\mathrm{N}}\right)$ of metals in RDS with different grain sizes along the urban-rural gradient.

\begin{tabular}{|c|c|c|c|c|c|c|c|c|c|c|c|c|c|c|c|}
\hline \multirow{3}{*}{$\begin{array}{l}\text { Grain size of } \\
\operatorname{RDS}(\mu \mathrm{m})\end{array}$} & \multicolumn{15}{|c|}{ Urban-rural gradient $^{\mathrm{a}}$} \\
\hline & \multicolumn{3}{|l|}{ UCA } & \multicolumn{3}{|l|}{ CSA } & \multicolumn{3}{|l|}{ RTA } & \multicolumn{3}{|l|}{ RVA } & \multicolumn{3}{|l|}{ UVA } \\
\hline & $\overline{{\overline{P_{i j}}}^{b} \mathrm{~b}}$ & $\operatorname{Max} P_{i j}$ & $\mathrm{PI}_{\mathrm{N}}$ & $\overline{P_{i j}}$ & $\operatorname{Max} P_{i j}$ & $\mathrm{PI}_{\mathrm{N}}$ & $\overline{P_{i j}}$ & $\operatorname{Max} P_{i j}$ & $\mathrm{PI}_{\mathrm{N}}$ & $\overline{\overline{P_{i j}}}$ & $\operatorname{Max} P_{i j}$ & $\mathrm{PI}_{\mathrm{N}}$ & $\overline{\overline{P_{i j}}}$ & $\operatorname{Max} P_{i j}$ & $\mathrm{PI}_{\mathrm{N}}$ \\
\hline$<44$ & 4.82 & 13.14 & 9.90 & 3.90 & 21.49 & 15.44 & 3.30 & 13.04 & 9.51 & 2.35 & 9.343 & 6.87 & 3.98 & 10.57 & 7.99 \\
\hline $44-62$ & 4.05 & 11.35 & 8.52 & 3.27 & 19.64 & 14.08 & 2.69 & 9.08 & 6.70 & 1.92 & 7.38 & 5.39 & 3.43 & 7.56 & 5.87 \\
\hline $62-105$ & 3.61 & 10.16 & 7.63 & 2.61 & 12.58 & 9.09 & 2.14 & 7.89 & 5.78 & 1.63 & 7.01 & 5.09 & 2.68 & 6.41 & 4.91 \\
\hline $105-149$ & 3.32 & 10.56 & 7.83 & 2.54 & 10.60 & 7.71 & 2.11 & 8.21 & 5.99 & 1.64 & 6.23 & 4.56 & 2.42 & 6.32 & 4.79 \\
\hline $149-250$ & 2.92 & 12.81 & 9.29 & 1.95 & 10.04 & 7.23 & 1.58 & 7.65 & 5.52 & 1.41 & 8.12 & 5.83 & 2.19 & 6.25 & 4.68 \\
\hline $250-450$ & 1.71 & 5.92 & 4.36 & 1.40 & 13.45 & 9.56 & 1.19 & 5.42 & 3.92 & 1.01 & 5.16 & 3.72 & 1.25 & 3.63 & 2.72 \\
\hline $450-1000$ & 1.39 & 6.94 & 5.01 & 1.22 & 11.09 & 7.89 & 1.20 & 10.22 & 7.27 & 0.90 & 6.08 & 4.35 & 1.38 & 6.02 & 4.36 \\
\hline $1000-2000$ & 1.11 & 8.71 & 6.21 & 1.11 & 9.82 & 6.99 & 0.81 & 3.68 & 2.67 & 0.84 & 6.64 & 4.74 & 1.47 & 11.72 & 8.35 \\
\hline $0-2000$ & 3.02 & 8.70 & 6.51 & 2.20 & 11.05 & 7.97 & 1.71 & 5.19 & 3.87 & 1.38 & 4.50 & 3.33 & 2.10 & 4.87 & 3.75 \\
\hline
\end{tabular}

a $\mathrm{UCA}=$ central urban area; UVA = urban village area; CSA = central suburban county area; RTA = rural town area; RVA = rural village area.

b $\mathrm{PI}_{\mathrm{N}}$ is the Nemerow's synthetical pollution index, $\overline{P_{i j}}$ and Max $P_{i j}$ is the maximum and average value of the pollution indices of all metals, respectively. 

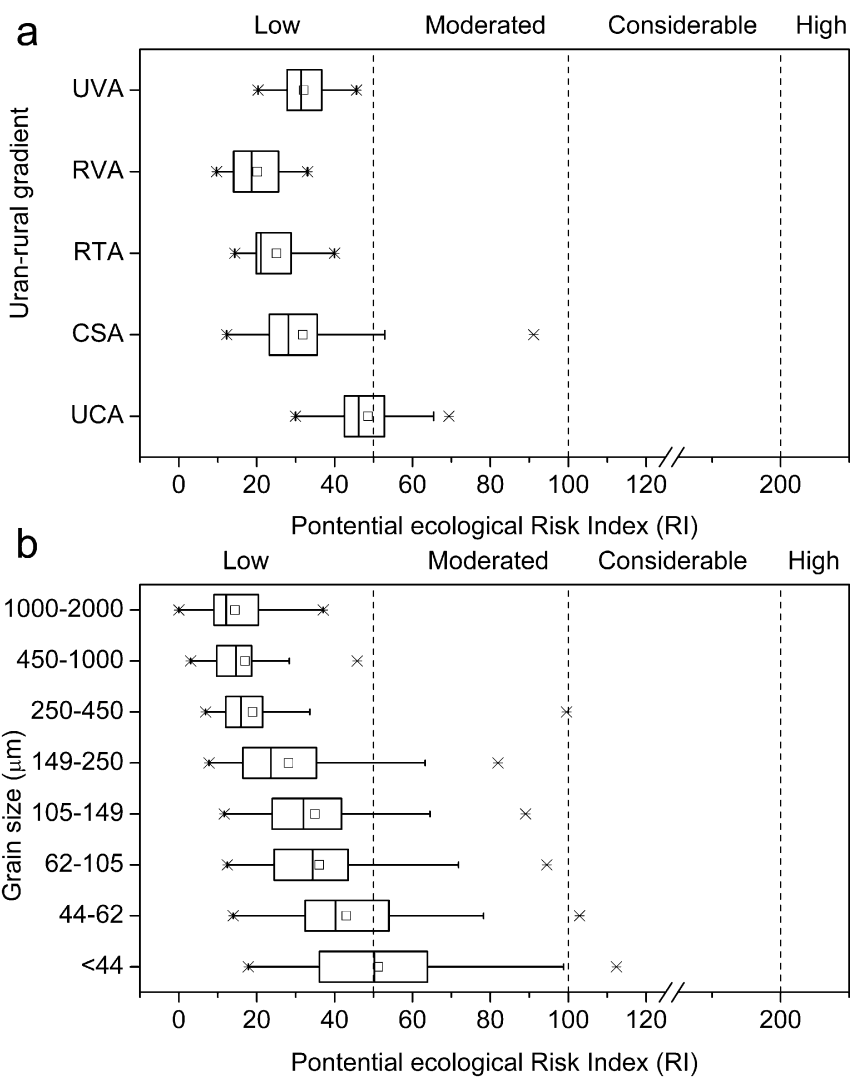

Fig. 4. Box plot of potential ecological risk index (RI) of metals in road-deposited sediment of Beijing: (a) urban-rural gradient and (b) grain size gradient. $\mathrm{UCA}=$ central urban area; UVA = urban village area; $\mathrm{CSA}=$ central suburban county area; $\mathrm{RTA}=$ rural town area; RVA = rural village area.

be improved when the RDS grain size was considered. The results above implied that consideration of particle grain size helped better understand metal risk. In addition, the RDS grain size had an important influence on the mobility of particles and their associated pollutant concentrations (Roger et al., 1998; Murakami et al., 2005; Deletic and Orr, 2009). The amount was another critical factor affecting RDS potential pollutants contribution to water. Thus, assessment of metal risk in RDS should not only consider the total concentration and toxicity of pollutants, but also their mobility and amount. The assessment results for the same gradient units using different methods (Table 6) demonstrated that RDS characteristics varied among the administration division units with the urban-rural gradient must be considered in metal risk

Table 4

The factor of mobility of road-deposited sediments with different grain size per unit area and per mass along the urban-rural gradient.

\begin{tabular}{lllllllll}
\hline $\begin{array}{l}\text { Mobility } \\
\text { factor }^{\mathrm{a}}\end{array}$ & \multicolumn{6}{l}{ Grain size $(\mu \mathrm{m})$} \\
\cline { 2 - 9 } & $<44$ & $44-$ & $62-$ & $105-$ & $149-$ & $250-$ & $450-$ & $0-$ \\
& & 62 & 105 & 149 & 250 & 450 & 1000 & 1000 \\
\hline UCA $^{\mathrm{b}}$ & 0.61 & 0.87 & 1.62 & 0.46 & 0.50 & 0.20 & 0.08 & $\mathbf{4 . 3 5}$ \\
CSA & 0.47 & 0.55 & 1.46 & 0.52 & 0.63 & 0.22 & 0.08 & $\mathbf{3 . 9 3}$ \\
RTA & 0.43 & 0.49 & 1.14 & 0.46 & 0.61 & 0.26 & 0.08 & $\mathbf{3 . 4 8}$ \\
RVA & 0.43 & 0.52 & 1.37 & 0.42 & 0.61 & 0.24 & 0.08 & $\mathbf{3 . 6 6}$ \\
UVA & 0.30 & 0.33 & 1.13 & 0.49 & 0.75 & 0.30 & 0.09 & $\mathbf{3 . 3 8}$ \\
\hline
\end{tabular}

${ }^{\text {a }}$ Mobility factor was calculated by the grain size response factors for potential mobility in runoff $\left(M_{j}\right)$ and the mass percentage of road-deposited sediments $\left(P_{j}\right)$.

${ }^{\mathrm{b}} \mathrm{UCA}=$ central urban area; UVA = urban village area; CSA = central suburban county area; RTA = rural town area; RVA = rural village area.
Table 5

The product of mobility and amount factors of road-deposited sediments along the urban-rural gradient.

\begin{tabular}{|c|c|c|c|c|c|}
\hline \multirow{2}{*}{$\begin{array}{l}\text { Product of amount } \\
\text { and mobility }\end{array}$} & \multicolumn{5}{|c|}{ The urban-rural gradient } \\
\hline & $\mathrm{UCA}^{\mathrm{b}}$ & CSA & RTA & RVA & UVA \\
\hline Mobility factor & 4.35 & 3.93 & 3.48 & 3.66 & 3.38 \\
\hline Amount factor ${ }^{\mathrm{a}}$ & 1.00 & 1.00 & 1.75 & 3.50 & 3.50 \\
\hline $\begin{array}{l}\text { Product of two } \\
\text { factors above }\end{array}$ & 4.35 & 3.93 & 6.09 & 12.81 & 11.83 \\
\hline
\end{tabular}

a Road-deposited sediment for UCA, CSA, RTA, RVA and UVA were 20, 20, 50, 150 and $150 \mathrm{~g} / \mathrm{m}^{2}$, respectively. The value of amount factor was get from road-deposited sediment levels.

${ }^{\mathrm{b}} \mathrm{UCA}=$ central urban area; UVA $=$ urban village area; $\mathrm{CSA}=$ central suburban county area; RTA = rural town area; RVA = rural village area.

assessment. The differences of the assessment results for the same gradient units using different methods were caused by the combination of the differences in the methods themselves (e.g., the assessing focus and base, index types, components) and those in RDS characteristics (e.g., metals concentrations, metal species, metal toxicity, RDS amount, grain size composition, RDS mobility). The differences in the methods themselves (e.g., the assessing focus and base, index types, components) were listed in Table 1. Clearly, $\mathrm{RI}_{\mathrm{RDS}}$ should contribute to the comprehensive assessment of metals risk in RDS along an urban-rural gradient.

In the method of $\mathrm{RI}_{\mathrm{RDS}}$, the parameters estimation for the mobility and amount is critical. Because of the data limits of the RDS mass per unit area in current references (Sartor and Boyd, 1972; Pitt et al., 2005), the divisions of the amounts were primarily based on our in-situ investigation of the RDS mass per unit area. To get better RDS parameter estimation, we had to use a large investigation number (total 167 sites; main traffic road areas, 97 sites; residential areas, 70 sites) along urban-rural gradients. The RDS mass per unit area varied in a broad range of $2-570 \mathrm{~g} / \mathrm{m}^{2}$ with a mean value $70 \mathrm{~g} / \mathrm{m}^{2}$. We found that places with larger RDS mass per unit area also had higher proportions of coarser particles. Accordingly, we assigned a comparatively lower level value for the range of larger RDS mass per unit area because coarser particles had lower risk of metal toxicity and mobility. In addition, other factors such as metal chemical fractions could be considered in future studies to provide a better understanding of metals toxicity (McAlister et al., 2005; Kartal et al., 2006).

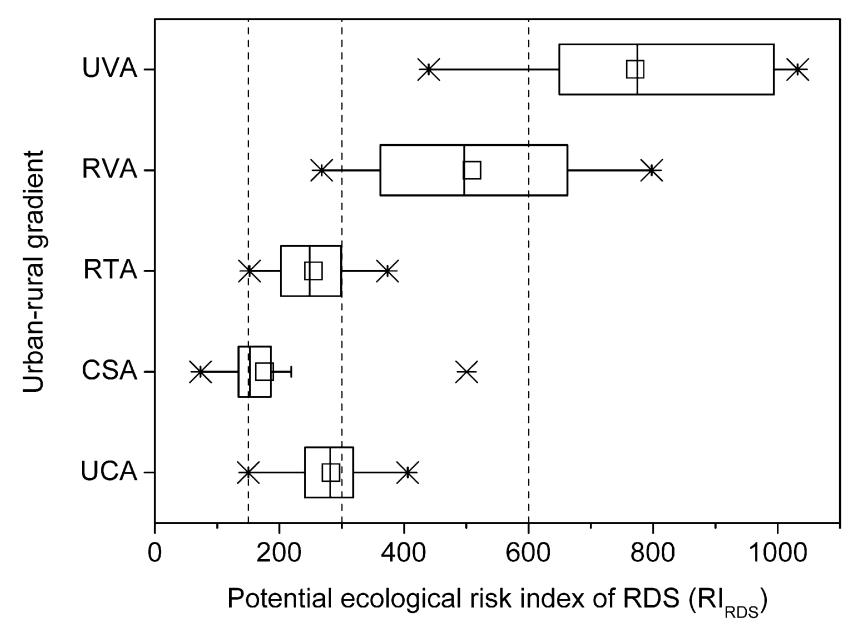

Fig. 5. Box plot of potential ecological risk index ( $\mathrm{RI}_{\mathrm{RDS}}$ ) of metals in road-deposited sediment of Beijing. UCA = central urban area; UVA = urban village area; $\mathrm{CSA}=$ central suburban county area; RTA = rural town area; RVA = rural village area 
Table 6

The difference of the assessment results among risk assessment methods.

\begin{tabular}{|c|c|}
\hline Assessment methods ${ }^{\mathrm{a}}$ & $\begin{array}{l}\text { The risk level order of } 5 \text { administrative } \\
\text { units }^{\text {b }}\end{array}$ \\
\hline Direct comparison & $\mathrm{UCA}>\mathrm{CSA} \approx \mathrm{UVA}>\mathrm{RTA}>\mathrm{RVA}$ \\
\hline Geoaccumulation index (Igeo $)$ & $\mathrm{UCA}>\mathrm{CSA} \approx \mathrm{UVA}>\mathrm{RTA}>\mathrm{RVA}$ \\
\hline Nemerow pollution index $\left(\mathrm{PI}_{\mathrm{N}}\right)$ & $\mathrm{CSA}>\mathrm{UCA}>\mathrm{RTA}>\mathrm{UVA}>\mathrm{RVA}$ \\
\hline $\begin{array}{l}\text { Potential ecological risk index } \\
\quad(\mathrm{RI})\end{array}$ & $\mathrm{UCA}>\mathrm{UVA}>\mathrm{CSA}>\mathrm{RTA}>\mathrm{RVA}$ \\
\hline $\begin{array}{l}\text { Modified potential ecological } \\
\left.\text { risk index ( } \mathrm{RI}_{\mathrm{RDS}}\right)\end{array}$ & UVA $>$ RVA $>$ UCA $>$ RTA $>$ CSA \\
\hline
\end{tabular}

a The methods of comparison and geoaccumulation index were both single index for each metal, their assessment results were for all metals combined.

b UCA = central urban area; UVA = urban village area; CSA = central suburban county area; $\mathrm{RTA}=$ rural town area; $\mathrm{RVA}=$ the rural village area.

\section{Conclusions}

We compared and analyzed the applicability of the traditional assessment method for metals risk based on data from central urban (UCA), urban village (UVA), central suburban county (CSA), rural town (RTA), and rural village (RVA) areas in Beijing. The spatial pattern of relative risk levels along the urban-rural gradient differed from the results using different assessment methods (e.g., direct comparison, geoaccumulation index, Nemerow pollution index and potential ecological risk index). The risk level associated with metal changed significantly when grain size was considered in each traditional assessment method, and it helped understand metal risk. To investigate the impacts by metal total concentration, metal toxicity, RDS amount, grain size composition and mobility, we developed a new risk index by adding the factors RDS amount and mobility to the modified potential ecological risk index. The metal risk levels for water pollution using $\mathrm{RI}_{\mathrm{RDS}}$ decreased in the order of UVA $>$ RVA $>$ UCA $>$ RTA $>$ CSA, which did not followed the variation order of RDS amount, or metal concentrations along the urban-rural gradient. Our results demonstrated that RDS characteristics varied among the administration division units with the urban-rural gradient must be considered in metal risk assessment.

\section{Acknowledgments}

We are grateful to Chengqing Yin for helpful suggestions, to Jingjun Su and Jeremy Kamen for their language corrections of the manuscript, to Xiaoyan He, Xiaoxue Wang, Xiaomei Wang, Huiliang Wang, Yang Ouyang, Xinzhong Du, Wenzan Li, and Shuxia He for their help collecting road-deposited sediment. Funding was supported by the National Natural Science Foundation of China (No. 41171395) and the Major Science and Technology Program for Water Pollution Control and Treatment (No. 2012ZX07029-002, 2012ZX07203-003).

\section{References}

Al-Khashman, O.A., 2004. Heavy metal distribution in dust, street dust and soils from the work place in Karak Industrial Estate, Jordan. Atmospheric Environment 38, 6803-6812.

Andrews, S., Sutherland, R.A., 2004. $\mathrm{Cu}, \mathrm{Pb}$ and $\mathrm{Zn}$ contamination in Nuuanu watershed, Oahu, Hawaii. Science of the Total Environment 324, 173-182.

Buccolieri, A., Buccolieri, G., Cardellicchio, N., Dell'Atti, A., Di Leo, A., Maci, A., 2006. Heavy metals in marine sediments of Taranto Gulf (Ionian Sea, southern Italy). Marine Chemistry 99, 227-235.

Caeiro, S., Costa, M., Ramos, T., Fernandes, F., Silveira, N., Coimbra, A., Medeiros, G., Painho, M., 2005. Assessing heavy metal contamination in Sado Estuary sediment: an index analysis approach. Ecological Indicators 5, 151-169.

Callender, E., Rice, K.C., 2000. The urban environmental gradient: anthropogenic influences on the spatial and temporal distributions of lead and zinc in sediments. Environmental Science and Technology 34, 232-238.
Charlesworth, S., De Miguel, E., Ordóñez, A., 2011. A review of the distribution of particulate trace elements in urban terrestrial environments and its application to considerations of risk. Environmental Geochemistry and Health 33, 103-123.

Chen, T., Zheng, Y., Chen, H., Zheng, G., 2004. Background concentrations of soil heavy metals in Beijing. Chinese Journal of Environmental Science 25, 117-122 (in Chinese).

Cheng, J., Shi, Z., Zhu, Y., 2007. Assessment and mapping of environmental quality in agricultural soils of Zhejiang Province, China. Journal of Environmental Sciences $19,50-54$.

Christoforidis, A., Stamatis, N., 2009. Heavy metal contamination in street dust and roadside soil along the major national road in Kavala's region, Greece. Geoderma 151, 257-263.

Deletic, A., Orr, D.W., 2009. Pollution buildup on road surfaces. Journal of Environmental Engineering 131, 49-59.

Deng, F.F., Huang, Y., 2004. Uneven land reform and urban sprawl in China: the case of Beijing. Progress in Planning 61, 211-236.

Duong, T.T.T., Lee, B.K., 2009. Partitioning and mobility behavior of metals in road dusts from national-scale industrial areas in Korea. Atmospheric Environment 43, 3502-3509.

Duzgoren-Aydin, N.S., 2007. Sources and characteristics of lead pollution in the urban environment of Guangzhou. Science of the Total Environment 385, 182-195.

Eriksson, E., Baun, A., Scholes, L., Ledin, A., Ahlman, S., Revitt, M., Noutsopoulos, C., Mikkelsen, P.S., 2007. Selected stormwater priority pollutants: a European perspective. Science of the Total Environment 383, 41-51.

Gong, Q., Deng, J., Xiang, Y., Wang, Q., Yang, L., 2008. Calculating pollution indices by heavy metals in ecological geochemistry assessment and a case study in parks of Beijing. Journal of China University of Geosciences 19, 230-241.

Hakanson, L., 1980. An ecological risk index for aquatic pollution control. A sedimentological approach. Water Research 14, 975-1001.

Herngren, L., Goonetilleke, A., Ayoko, G.A., 2005. Understanding heavy metal and suspended solids relationships in urban stormwater using simulated rainfall. Journal of Environmental Management 76, 149-158.

Kartal, S., Aydin, Z., Tokalioglu, S., 2006. Fractionation of metals in street sediment samples by using the BCR sequential extraction procedure and multivariate statistical elucidation of the data. Journal Hazardous Materials 132, 80-89.

Kim, J.Y., Sansalone, J.J., 2008. Event-based size distributions of particulate matter transported during urban rainfall-runoff events. Water Research 42, 27562768.

Kong, S., Lu, B., Ji, Y., Zhao, X., Bai, Z., Xu, Y., Liu, Y., Jiang, H., 2012. Risk assessment of heavy metals in road and soil dusts within PM2.5, PM10 and PM100 fractions in Dongying city, Shandong Province, China. Journal of Environmental Monitoring 14, 791-803.

Kupiainen, K.J., Tervahattu, H., Räisänen, M., Mäkelä, T., Aurela, M., Hillamo, R., 2005. Size and composition of airborne particles from pavement wear, tires, and traction sanding. Environmental Science and Technology 39, 699-706.

Lau, S.L., Stenstrom, M.K., 2005. Metals and PAHs adsorbed to street particles. Water Research 39, 4083-4092.

Liu, H., Li, L., Yin, C., Shan, B., 2008. Fraction distribution and risk assessment of heavy metals in sediments of Moshui Lake. Journal of Environmental Sciences 20, 390-397.

Lu, X., Wang, L., Lei, K., Huang, J., Zhai, Y., 2009. Contamination assessment of copper, lead, zinc, manganese and nickel in street dust of Baoji, NW China. Journal Hazardous Materials 161, 1058-1062.

McAlister, J.J., Smith, B.J., Neto, J.B., Simpson, J.K., 2005. Geochemical distribution and bioavailability of heavy metals and oxalate in street sediments from Rio de Janeiro, Brazil: a preliminary investigation. Environmental Geochemistry and Health 27, 429-441.

Müller, G., 1969. Index of geoaccumulation in sediments of the Rhine River. Geojournal 2, 108-118.

Murakami, M., Nakajima, F., Furumai, H., 2005. Size- and density-distributions and sources of polycyclic aromatic hydrocarbons in urban road dust. Chemosphere 61, 783-791.

Pitt, R., Williamson, D., Voorhees, J., 2005. Review of historical street dust and dirt accumulation and washoff data. In: James, W., Irvine, K.N., McBean, E.A., Pitt, R.E. (Eds.), Effective Modeling of Urban Water Systems. Monograph 13. CHI, Guelph, Ontario, pp. 203-246.

Roger, S., Montrejaud-Vignoles, M., Andral, M.C., Herremans, L., Fortune, J.P., 1998. Mineral, physical and chemical analysis of the solid matter carried by motorway runoff water. Water Research 32,1119-1125.

Rogge, W.F., Hildemann, L.M., Mazurek, M.A., Cass, G.R., Simoneit, B.R.T., 1993. Sources of fine organic aerosol. 3. Road dust, tire debris, and organometallic brake lining dust: roads as sources and sinks. Environmental Science and Technology 27, 1892-1904.

Sartor, J.D., Boyd, G.B., 1972. Water pollution aspects of street surface contaminants. In: EPA-r2-72-081, U.S. Environmental Protection Agency.

Shi, G., Chen, Z., Bi, C., Li, Y., Teng, J., Wang, L., Xu, S., 2010. Comprehensive assessment of toxic metals in urban and suburban street deposited sediments (SDSs) in the biggest metropolitan area of China. Environmental Pollution 158, 694-703.

Sutherland, R.A., Tack, F.M.G., Ziegler, A.D., 2012. Road-deposited sediments in an urban environment: a first look at sequentially extracted element loads in grain size fractions. Journal of Hazardous Materials 225-256, 54-62. 
Sutherland, R.A., Tolosa, C.A., 2000. Multi-element analysis of road-deposited sediment in an urban drainage basin, Honolulu, Hawaii. Environmental Pollution $110,483-495$.

Tessier, A., Campbell, P.G.C., Bisson, M., 1979. Sequential extraction procedure for the speciation of particulate trace metals. Analytical Chemistry 51, 844-851.

Thorpe, A., Harrison, R.M., 2008. Sources and properties of non-exhaust particulate matter from road traffic: a review. Science of the Total Environment 400, 270282

Tian, P., Li, Y., Yang, Z., 2009. Effect of rainfall and antecedent dry periods on heavy metal loading of sediments on urban roads. Frontiers of Earth Science in China 3, 297-302.

Wei, B., Yang, L., 2010. A review of heavy metal contaminations in urban soils, urban road dusts and agricultural soils from China. Microchemical Journal 94, 99-107.

Xiang, L., Li, Y., Yang, Z., Shi, J., 2010. Seasonal difference and availability of heavy metals in street dust in Beijing. Journal of Environmental Science and Health
Part A: Toxic/Hazardous Substances and Environmental Engineering 45, 1092 1100.

Yuen, J., Olin, P.H., Lim, H., Benner, S.G., Sutherland, R., Ziegler, A., 2012. Accumulation of potentially toxic elements in road deposited sediments in residentia and light industrial neighborhoods of Singapore. Journal of Environmental Management 101, 151-163.

Zhao, H., Li, X., Wang, X., 2011. Heavy metal content of road-deposited sediment along the urban-rural gradient around Beijing and its potential contribution to runoff pollution. Environmental Science and Technology 45, 7120-7127.

Zhao, H., Li, X., Wang, X., Tian, D., 2010. Grain size distribution of road-deposited sediment and its contribution to heavy metal pollution in urban runoff in Beijing, China. Journal of Hazardous Materials 183, 203-210.

Zhu, W., Bian, B., Li, L., 2008. Heavy metal contamination of road-deposited sediments in a medium size city of China. Environmental Monitoring and Assessment $147,171-181$ 